Disponível em:

http://editora.unoesc.edu.br/index.php/race

Race, Joaçaba, v. 15, n. 3, p. 1117-1142, set./dez. 2016

\title{
A COMPARABILIDADE DAS ESCOLHAS CONTÁBEIS NA MENSURAÇÃO DE ATIVOS INTANGÍVEIS DE COMPANHIAS ABERTAS BRASILEIRAS E PORTUGUESAS
}

The Comparability of Accounting Choices in the Measurement of Intangible Assets of Brazilian and Portuguese Listed Companies

Flaida Êmine Alves de Souza

E-mail: flaidaemine@yahoo.com.br

Mestre em Contabilidade Financeira pela Universidade Federal de Uberlândia; Especialista em Direito Público pela Universidade Anhanguera.

Reiner Alves Botinha

E-mail: reiner.botinha@gmail.com

Mestre em Ciências Contábeis na linha de Contabilidade Financeira pela Universidade Federal de Uberlândia; Doutorando em Ciências Contábeis na Universidade Federal de Uberlândia; Professor dos Cursos de Graduação em Ciências Contábeis na Universidade Federal de Uberlândia. Endereço para contato: Avenida João Naves de Ávila, 2121, Santa Mônica, 38408-100, Uberlândia, Minas Gerais, Brasil.

Sirlei Lemes

E-mail: sirlemes@uol.com.br

Doutora e Mestre em Controladoria e Contabilidade pela Universidade de São Paulo; Professora de Ciências Contábeis na Universidade Federal de Uberlândia.

Artigo recebido em 12 de agosto de 2015. Aceito em 06 de maio de 2016. 


\section{Resumo}

Com o fluxo das relações entre os mercados financeiros, surge a importância da comparabilidade das demonstrações contábeis entre entidades de um mesmo país, assim como entre entidades de países diferentes. Nesse sentido, com o estudo buscou-se identificar o grau de comparabilidade das demonstrações financeiras de 230 companhias abertas, sendo 184 entidades do Brasil e 43 entidades de Portugal, em relação às escolhas contábeis em ativos intangíveis (IAS 38), no período de 2010 a 2012. As escolhas contábeis analisadas relacionaram-se à mensuração dos ativos intangíveis, ou seja, ao reconhecimento, à avaliação e ao impairment. A comparabilidade dentro e entre países foi medida pelo índice $\mathrm{T}$ (Índice de Taplin), e buscou-se verificar o comportamento do índice ao longo do período analisado. Os resultados mostraram que, apesar das escolhas contábeis presentes na norma IAS 38, observou-se comparabilidade entre as práticas contábeis em ativos intangíveis das empresas do Brasil e de Portugal, em todos os períodos analisados. Entretanto, essa comparabilidade registrou-se média e decrescente ao longo do tempo. Fato curioso aponta maiores índices de comparabilidade em itens com maior número de escolhas contábeis. Outro resultado a se destacar é que, apesar de as empresas brasileiras exibirem maior comparabilidade, as empresas portuguesas apresentaram-se mais harmônicas no sentido de as entidades manterem as mesmas escolhas contábeis ao longo do tempo.

Palavras-chave: Comparabilidade. Escolhas contábeis. Ativo intangível. Índice T.

\section{Abstract}

With the flow of the relationship between financial markets, arises the importance of comparability of financial statements between entities within a country and between entities of different countries. In this sense, with the study it was seeked to identify the degree of comparability of financial statements of 230 listed companies, with 184 entities in Brazil and 43 entities in Portugal, in relation to the accounting choices in intangible assets (IAS 38) for the period from 2010 to 2012. The analyzed accounting choices related to the measurement of intangible assets, ie the recognition, evaluation and impairment. The comparability within and between countries was measured by T-score (Taplin Index), and sought to verify the behavior of the index over the period analyzed. The results showed that despite the accounting choices present in the standard IAS 38, it observed comparability between the accounting practices in intangible assets of companies from Brazil and Portugal, in all periods analyzed. However, this comparison recorded medium and decreasing over time. Interesting fact points greater comparability rates on items with the highest number of accounting choices. Another result to stand out, is that although Brazilian companies exhibit greater comparability, Portuguese companies presented more harmonic towards the entities remain the same accounting choices over time.

Keywords: Comparability. Accounting choices. Intangible asset. T-Index. 


\section{INTRODUÇÃO}

O International Accounting Standards Board (IASB) e o Financial Accounting Standards Board (FASB), desde que foi assinado o Acordo de Norwalk em 2001, continuam a colaborar na busca de um único conjunto de normas contábeis que possa servir para uma contabilidade prática (TUDOR; DRAGU, 2010). A intenção é que se desenvolvam normas contábeis de alta qualidade, compreensíveis e com padrões contábeis que possam ser mundialmente aplicados (PENG; SMITH, 2010).

Com a integração entre os mercados financeiros, tornou-se possível que investidores empreguem recursos em qualquer lugar do mundo, independentemente de residir no país onde o seu capital esteja alocado (OLIVEIRA; LEMES, 2011). Nesse sentido, destaca-se a importância de se terem demonstrações contábeis comparáveis, tanto entre entidades de um mesmo país, ao longo do tempo, quanto entre entidades de países diferentes, considerando que as informações financeiras são a base para a tomada de decisões por parte dos investidores (CAIRNS et al., 2011; OLIVEIRA; LEMES, 2011).

Desde 2001, quase 120 países requereram ou permitiram o uso das International Financial Reporting Standards (IFRS) (2013), que são as normas internacionais de contabilidade. Alguns números aclaram a importância que a convergência contábil internacional ganhou nos últimos anos: “[...] dos 36 trilhões de dólares capitalizados dos mercados mundiais no final de 2005, em torno de 11 trilhões correspondiam a mercados em que as IFRS eram exigidas ou permitidas.” (LEMES; CARVALHO, 2009, p. 26).

As bolsas de valores da União Europeia, a exemplo a bolsa de Portugal, por meio do Regulamento n. 1.606/2002 emitido pelo Parlamento Europeu, aderiram às IFRS a partir do exercício findo em 31 de dezembro de 2005, como forma de estímulo ao fluxo de capital entre seus países membros (EUROPEAN PARLIAMENT, 2002; OLIVEIRA; LEMES, 2011; KPMG, 2013). Conforme dispõe o European Parliament (2002, p. 1), “[...] um único conjunto de normas contábeis é essencial para assegurar um elevado grau de transparência e comparabilidade das demonstrações financeiras e, consequentemente, o funcionamento eficiente do mercado de capitais da União Europeia e do Mercado Interno.”

O Brasil veio ao encontro desse movimento mundial, quando, em 2007, a Comissão de Valores Mobiliários (CVM) aprovou a Instrução n. 457, tornando obrigatória a adoção das IFRS para as companhias abertas do Brasil, a partir do exercício findo em 31 de dezembro de 2010 (OLIVEIRA; LEMES, 2011). A intenção, ao se 
aderir às IFRS, foi, segundo Oliveira e Lemes (2011): tornar as informações contábeis comparáveis; promover a transparência e a confiabilidade das demonstrações financeiras; e ampliar a acessibilidade ao mercado mundial de capitais.

A adoção das IFRS, no Brasil, foi realizada por meio do Comitê de Pronunciamentos Contábeis (CPC), órgão criado em razão das necessidades de convergência internacional, da centralização na emissão de normas e da representação em processos democráticos na produção de tais normas (COMITÊ DE PRONUNCIAMENTOS CONTÁBEIS, 2013a). As normas internacionais de contabilidade (denominadas no Brasil Pronunciamento Técnico CPC ou simplesmente CPC) são de aplicação obrigatória para todas as companhias abertas brasileiras e são recepcionadas integralmente pelo Brasil, com raras adaptações.

Uma das normas internacionais de contabilidade emitidas pelo IASB foi a Intangible Assets (IAS 38), recepcionada pelo Brasil mediante o Pronunciamento Técnico CPC 04 e pela União Europeia por meio da Norma Internacional de Contabilidade 38 (COMITÊ DE PRONUNCIAMENTOS CONTÁBEIS, 2013b; GOLDMAN ACADEMY, 2013). Essa norma surgiu da necessidade de se definir o tratamento contábil dos ativos intangíveis, visto que eles têm se tornado cada vez mais significativos para um grande número de empresas (KUMAR, 2013). Com o aumento da materialidade dos valores desses ativos na composição do patrimônio das empresas, surgiram problemas sobre como tratar contabilmente esses elementos (SCHMIDT; SANTOS, 2003).

Melhorar a comparabilidade das informações contábeis divulgadas é um dos principais objetivos das IFRS (CAIRNS et al., 2011). Em consequência, o IASB tem a intenção de não permitir escolhas contábeis (Prefácio às IFRS, parágrafo 13, 2007), que são critérios alternativos de reconhecimento, mensuração e evidenciação de informações econômico-financeiras, a fim de possibilitar maior comparabilidade entre as demonstrações financeiras. Entretanto, assim como as demais normas internacionais de contabilidade, a IAS 38 dispõe de escolhas contábeis em algumas de suas principais formas de mensuração.

Nesse sentido, o objetivo que orientou a realização deste estudo foi identificar o grau de comparabilidade das demonstrações financeiras das companhias abertas do Brasil e de Portugal, em relação às escolhas contábeis para ativos intangíveis. Escolheram-se esses dois países, pois a relação entre Brasil e Portugal é antiga. Originou-se na colonização do Brasil em 1500, passando pela criação do Comércio da Corte em 1809 (quando houve a adoção do sistema de partidas dobradas para o controle dos bens), estendendo-se até os dias atuais, quando se percebe que as duas nações adota- 
ram as IFRS (PELEIAS; BACCI, 2004; LEITE, 2005) e mantêm relações comerciais intensificadas (BRASIL..., 2013).

Para a composição da amostra, foram coletados os dados das demonstrações financeiras de 184 entidades brasileiras listadas na Bolsa de Valores, Mercadorias e Futuros de São Paulo (BM\&FBOVESPA) e 46 entidades portuguesas listadas na NYSE Euronext Lisbon (Bolsa de Valores de Lisboa), em 2013, para os períodos de 2010 a 2012.

Este estudo contribui com a prática contábil, ao demonstrar aos usuários das demonstrações contábeis se elas são equiparáveis entre entidades de um mesmo país, ao longo do tempo, e entre países, o que possibilita uma melhor análise econômico-financeira das empresas. Contribui com os elaboradores das normas contábeis, ao demonstrar se, na prática, a IAS 38, apesar da existência de escolhas contábeis, tem permitido a comparabilidade das demonstrações financeiras, como objetiva o IASB.

A presente pesquisa está estruturada em cinco partes, a contar desta introdução. Na seção dois, tem-se o referencial teórico; na seção três, são expostos os aspectos metodológicos; na seção quatro, descrevem-se e analisam-se os resultados; e, na última seção, têm-se as considerações finais sobre as evidências encontradas neste estudo.

\section{REFERENCIAL TEÓRICO}

Nesta revisão de literatura aborda-se o ativo intangível, apresentando-se suas definições, critérios de reconhecimento, de mensuração e regulamentações. Posteriormente, apresentam-se aspectos relacionados às escolhas contábeis, à comparabilidade das demonstrações contábeis e a estudos anteriores.

\subsection{REGULAMENTAÇÃO DO ATIVO INTANGÍVEL}

Ekberg e Lindgren (2007) trazem que uma das normas contábeis internacionais que têm sido frequentemente discutida, desde a implementação das IFRS, é a que diz respeito ao ativo intangível: a IAS 38. Atualmente, as empresas têm registrado valores expressivos de ativos intangíveis em seu balanço patrimonial, o que tornou as normas que os regulamentam um importante tópico de discussão para estudiosos e profissionais dentro da ciência contábil (EKBERG; LINDGREN, 2007).

Os principais pontos regulados pela IAS 38 “[...] envolvem questões relacionadas à natureza e ao reconhecimento dos ativos intangíveis, à mensuração dos 
custos e à contabilização da amortização e das perdas por impairment de tais ativos.” (LEMES; CARVALHO, 2010, p. 193).

De acordo com o item 10 da IAS 38 (2009), para que um elemento patrimonial seja reconhecido como ativo intangível, necessariamente, precisa ser identificável, controlado e gerador de benefícios econômicos futuros. Quanto à avaliação, a Norma Internacional traz que, inicialmente, um ativo intangível deve ser reconhecido pelo seu custo de aquisição ou custo de geração interna.

Para a mensuração após reconhecimento inicial (avaliação posterior), a norma estabelece que a entidade opte por reconhecer o ativo intangível pelo método de custo ou pelo método da reavaliação, adotando-o para todos os ativos restantes da sua classe, como uma definição de sua política contábil (IAS PLUS, 2009). No caso brasileiro, a reavaliação não é permitida em virtude da vedação trazida pela Lei n. 6.404/76. Portanto, para o Brasil não há opção pela reavaliação a valor justo, apenas pelo método de custo ou pela não evidenciação de tal informação (BRASIL, 2007; AVELINO; PINHEIRO; LAMOUNIER, 2012).

A norma traz, ainda, que ao fim de cada período a entidade deve avaliar se há indícios de que algum intangível tenha sofrido desvalorização. Se houver, a entidade deve estimar o valor recuperável desse ativo, comparando-o com o seu valor contábil (IAS 36, item 9, 2009; IAS 38, item 108, 2009). Porém, independentemente de existir algum indicativo de desvalorização, a entidade deve, obrigatoriamente, realizar o teste de recuperabilidade, no mínimo, anualmente, para: os ativos intangíveis com vida útil indefinida; os ativos intangíveis que não entraram em operação; e para o goodwill (IAS 36, item 10, 2009).

\subsection{ESCOLHAS CONTÁBEIS}

Com o surgimento das IFRS e seus propósitos intrínsecos, a contabilidade iniciou um processo de mudança de um ambiente ditado por normas para se fundamentar em princípios, tendo como escopo o subjetivismo profissional (julgamento profissional para a aplicação dos princípios) para a mensuração, o reconhecimento e a divulgação das transações contábeis (GABRIEL; CORRAR, 2010).

O IASB tem se esforçado para desenvolver padrões pautados em princípios; porém, a distinção entre padrões baseados em princípios e padrões baseados em regras é relativa (BARTH, 2008). As regras são informações mais detalhadas sobre a aplicação dos princípios, portanto, as IFRS incluem tanto princípios quanto regras, dependendo do contexto ao qual serão aplicadas (SCHIPPER, 2003; BARTH, 2008). 
Embora existam normas e orientações emanadas do IASB, o padrão internacional de contabilidade permite certa discricionariedade quando oferece mais de uma opção ao se reconhecer, mensurar e evidenciar determinados eventos contábeis (MARTINEZ, 2001; MURCIA; WERGES, 2011). Essa discricionariedade, decorrente de múltiplas opções de contabilizações, denomina-se escolhas contábeis.

Watts (1992) define escolhas contábeis como as alternativas permitidas aos gestores para reconhecer, mensurar e evidenciar os eventos contábeis no momento de seus registros, podendo, assim, optar por um método em detrimento de outro. $\mathrm{Na}$ visão de Fields, Lys e Vincent (2001, p. 256), as escolhas contábeis são:

[...] qualquer decisão, cujo objetivo principal é influenciar (seja na forma ou substância) a saída do sistema de contabilidade de uma forma particular, incluindo não apenas as demonstrações financeiras publicadas de acordo com o GAAP, mas também declarações fiscais e arquivamentos regulatórios.

Motivado na perspectiva de Fields, Lys e Vincent (2001), Goulart (2007, p. 42) ressalta que, em circunstâncias em que o gestor está diante de escolhas contábeis, sua decisão pode ser influenciada não apenas “[...] no que dita a realidade do evento econômico em análise, mas, por vezes, com base em outros fatores exógenos, que influenciam as decisões gerenciais, como os interesses particulares da empresa e do próprio gestor."

Em decorrência disso, estudos têm sido realizados visando a identificar a relação existente entre as escolhas contábeis e a prática no reconhecimento, na mensuração e na evidenciação das informações, bem como os impactos das escolhas contábeis na comparabilidade das demonstrações financeiras (CAIRNS et al., 2011; GE; MATSUMOTO; ZHANG, 2011; MURCIA; WERGES, 2011; LORENCINI; COSTA, 2012; HALLER; WEHRFRITZ, 2013; SOUZA; SILVA; COSTA, 2013).

A comparabilidade é um fator que pode ser afetado pelas escolhas contábeis (CAIRNS et al., 2011; SOUZA; SILVA; COSTA, 2013) e, portanto, é objeto de análise da presente pesquisa, sendo abordada na seção a seguir.

\subsection{COMPARABILIDADE DAS DEMONSTRAÇÕES CONTÁBEIS}

Malaquias (2008) salienta que, com o processo de convergência às IFRS, as práticas contábeis, em diferentes países, embora não sejam semelhantes, possibilitam 
que ativos, passivos, patrimônio líquido e contas de resultados de uma mesma empresa, independente do país no qual esteja localizada, não variem os valores.

Nesse mesmo sentido, conceituando o processo de convergência contábil, Lemes e Carvalho (2009, p. 33) entendem como “[...] um processo que ocorre no nível dos emissores de normas que buscam atingir um estado de harmonização contábil formal.” Se diferentes normativos estão se tornando convergentes, é provável que os valores contábeis de uma entidade que está sob as orientações dessa norma também estejam se aproximando ao longo dos períodos (LEMES; CARVALHO, 2009).

Os usuários das demonstrações contábeis necessitam de informações transparentes, confiáveis, de qualidade e comparáveis, pois, constantemente, encontram-se expostos a momentos de decisão, como investir em uma entidade ou em outra. Dessa forma, se os relatórios das empresas estiverem em bases comparáveis entre países, entre entidades e entre períodos, a informação contábil tornar-se-á mais útil (IAS, 2013).

Verifica-se que as normas internacionais trouxeram, como característica qualitativa para a elaboração da informação contábil-financeira útil, a comparabilidade, com outras características, como a relevância, a representação fidedigna, a verificabilidade, a tempestividade e a compreensibilidade (IAS, 2013). Em virtude disso, o Framework (2011), em seu item QC25, reza que “[...] a discricionariedade na escolha de métodos contábeis alternativos para o mesmo fenômeno econômico diminui a comparabilidade.”

Assim, Freri e Salotti (2013) questionaram a existência de comparabilidade entre as demonstrações contábeis das empresas com a opção de mensurar as propriedades para investimento pelo custo ou pelo valor justo. Os autores identificaram que a comparabilidade de muitas informações foi prejudicada por estas estarem em formatos diferentes de apresentação.

Posto que as IFRS possuem escolhas contábeis que podem afetar a comparabilidade proposta pelo IASB, foram desenvolvidos índices estatísticos com a finalidade de verificar se a convergência dos relatórios contábeis, na prática, tem ocorrido. Para Lemes e Carvalho (2009, p. 36), “[...] a comparação, ao longo do tempo, dos números obtidos por determinado índice permitiria a quantificação da harmonização.”

Van der Tas (1998) criou três índices (H, C e I) de forma a se mensurar o grau de comparabilidade dos relatórios contábeis, todos com a mesma finalidade, entretanto com características diferentes. No mesmo sentido, Taplin (2004), a partir dos índices criados por Van der Tas (1988), desenvolveu o índice T (T index), visando contemplar em um único indicador as especificidades dos anteriores. 
Há estudos, conforme o Quadro 1, que utilizaram os índices de comparabilidade para verificar, na prática contábil, se as normas internacionais têm conseguido assegurar a comparabilidade das demonstrações financeiras, como proposto pelo IASB.

Quadro 1 - Estudos anteriores sobre comparabilidade

\begin{tabular}{|c|c|}
\hline \multicolumn{2}{|c|}{ Stergios e Laskaridou (2008) } \\
\hline $\begin{array}{l}\text { Objetivo: Analisar se a adesão da Grécia às IFRS } \\
\text { atingiu a comparabilidade desejada e discutir } \\
\text { eventuais problemas que possam ter surgido. } \\
\text { Mensurar o grau de comparabilidade por meio } \\
\text { do cálculo do índice H, nos exercícios de } 2003 \\
\text { a } 2005 \text {. }\end{array}$ & $\begin{array}{l}\text { Resultados: Nos três períodos analisados, o índice } \\
\text { H foi positivo e estatisticamente significativo. A } \\
\text { qualidade da divulgação melhorou após a adoção } \\
\text { das IFRS. A convergência refletiu adequadamente } \\
\text { as diferentes circunstâncias em que as empresas } \\
\text { operaram. }\end{array}$ \\
\hline \multicolumn{2}{|c|}{ Cairns et al. (2011) } \\
\hline $\begin{array}{l}\text { Objetivo: Investigar o uso da mensuração do } \\
\text { valor justo de } 228 \text { companhias abertas do Reino } \\
\text { Unido e Austrália, quando da adoção das IFRS, } \\
\text { a partir de } 2005 \text {. Testar, por meio do cálculo } \\
\text { do índice T, se a comparabilidade das escolhas } \\
\text { contábeis, dentro e entre os países, mudou em } \\
\text { relação ao uso obrigatório e facultativo da men- } \\
\text { suração a valor justo. }\end{array}$ & $\begin{array}{l}\text { Resultados: Os resultados sugeriram uma abor- } \\
\text { dagem conservadora e/ou uma falta de incentivos } \\
\text { quanto à utilização da mensuração do valor justo } \\
\text { para a maioria das empresas. As exceções incluí- } \\
\text { ram alguns bancos e companhias de seguros (para } \\
\text { outros ativos e passivos financeiros) e as empresas } \\
\text { titulares de propriedades para investimento. }\end{array}$ \\
\hline \multicolumn{2}{|c|}{ Dragu (2010) } \\
\hline $\begin{array}{l}\text { Objetivo: Investigar o nível de harmonização } \\
\text { das normas contábeis nacionais e internacionais } \\
\text { (IFRS) e medir o grau de comparabilidade das } \\
\text { escolhas contábeis em ativos intangíveis de } 50 \\
\text { entidades listadas na bolsa de valores de Londres, } \\
\text { por meio do cálculo do índice H. }\end{array}$ & $\begin{array}{l}\text { Resultados: Os resultados mostraram uma ten- } \\
\text { dência de harmonização no que se refere aos } \\
\text { ativos intangíveis. Identificou-se um alto nível de } \\
\text { comparabilidade para o reconhecimento de ativos } \\
\text { intangíveis, uma tendência para a reconciliação } \\
\text { na valorização desses ativos, bem como práticas } \\
\text { comuns em matéria de impairment. }\end{array}$ \\
\hline \multicolumn{2}{|c|}{ Tudor e Dragu (2010) } \\
\hline $\begin{array}{l}\text { Objetivo: Demonstrar a existência de compa- } \\
\text { rabilidade entre as práticas contábeis em ativos } \\
\text { intangíveis de cinco países da União Europeia, } \\
\text { por meio do cálculo do índice H, como resultado } \\
\text { da adoção das IFRS. }\end{array}$ & $\begin{array}{l}\text { Resultados: Os resultados forneceram evidên- } \\
\text { cias de que as IFRS geraram práticas contábeis } \\
\text { comparáveis entre os países europeus, com mui- } \\
\text { tas situações demonstrando graus máximos de } \\
\text { comparabilidade. }\end{array}$ \\
\hline \multicolumn{2}{|c|}{ Souza, Silva e Costa (2013) } \\
\hline $\begin{array}{l}\text { Objetivo: Averiguar se as escolhas contábeis } \\
\text { contidas na IAS } 38 \text { permitem a comparabilidade } \\
\text { das demonstrações financeiras das companhias } \\
\text { abertas do Brasil. A comparabilidade foi medida } \\
\text { por meio do cálculo do índice H. }\end{array}$ & $\begin{array}{l}\text { Resultados: A IAS } 38 \text { permitiu a comparabilidade } \\
\text { dos ativos intangíveis das companhias abertas } \\
\text { brasileiras. Entretanto, em nenhuma das análises } \\
\text { o índice H obteve seu valor máximo ou próximo } \\
\text { a ele e comportou-se de maneira decrescente nos } \\
\text { períodos analisados. }\end{array}$ \\
\hline
\end{tabular}

Fonte: os autores.

Dessa forma, na presente pesquisa pretendeu-se contribuir com os achados, visando identificar a comparabilidade entre diferentes empresas de dois países, a partir das escolhas contábeis previstas na IAS 38 para ativos intangíveis. 


\section{ASPECTOS METODOLÓGICOS}

A amostra do estudo foi composta por 230 companhias abertas, sendo 184 brasileiras e 43 portuguesas para os exercícios de 2010 a 2012. A seleção dos países aconteceu em razão de suas similaridades históricas, porém, especialmente pela ampliação recente das relações comerciais entre Brasil e Portugal. Os anos 2010 e 2012 foram escolhidos em virtude da adoção obrigatória das IFRS para as companhias abertas das duas nações.

A identificação das entidades brasileiras, dos saldos do intangível e das notas explicativas ocorreu pelo site da BM\&FBOVESPA. No caso das entidades portuguesas, a busca pelas entidades foi feita pelo sítio eletrônico da Bolsa de Valores de Lisboa, e a busca dos saldos do intangível e das notas explicativas ocorreu pelo site da Comissão de Mercado de Valores Mobiliários de Portugal (CMVM). Na Tabela 1 apresenta-se a caracterização da amostra.

Tabela 1 - Amostra de entidades brasileiras e portuguesas em 2012

\begin{tabular}{|c|c|c|}
\hline \multirow{2}{*}{ DESCRIÇÃO DAS ENTIDADES } & \multicolumn{2}{|c|}{ PAÍSES } \\
\hline & BRASIL & PORTUGAL \\
\hline (=) Total de Entidades listadas nas bolsas de valores em 2013 & 528 & 52 \\
\hline $\begin{array}{l}\text { (-) Entidades excluídas por não serem companhias abertas em } \\
\text { algum dos períodos analisados }\end{array}$ & (38) & $(0)$ \\
\hline $\begin{array}{l}\text { (-) Entidades excluídas por não possuírem ativos intangíveis } \\
\text { reconhecidos em suas DFs em algum dos períodos analisados }\end{array}$ & $(134)$ & $(01)$ \\
\hline $\begin{array}{l}\text { (-) Entidades excluídas por pertencerem ao mesmo grupo con- } \\
\text { solidado }\end{array}$ & $(0)$ & $(05)$ \\
\hline (-) Entidades excluídas por não possuírem setor correspondente & (5) & $(0)$ \\
\hline $\begin{array}{l}\text { (-) Entidades excluídas pelo cálculo da amostra aleatória (inter- } \\
\text { valo de confiança }=95 \% \text { e erro máximo desejado = 5\%) }\end{array}$ & $(167)$ & $(0)$ \\
\hline (=) Número de entidades analisadas & 184 & 46 \\
\hline
\end{tabular}

Fonte: os autores.

Partindo-se da máxima de que “[...] a contabilidade será totalmente comparável quando todas as empresas que operam em circunstâncias semelhantes adotem o mesmo tratamento contábil para transações semelhantes, independentemente do seu domicílio” (JAAFAR; MCLEAY, 2007, p. 157), a análise deste estudo foi feita com base nos setores de atuação das empresas selecionadas. Assim, as entidades foram divididas por setor de atuação, proporcionalmente, a fim de possibilitar uma base comparável, conforme ilustrado na Tabela 2. 
Tabela 2 - Amostra de empresas por setor de atuação

\begin{tabular}{lrr}
\hline \multicolumn{1}{c}{ SETOR } & \multicolumn{2}{c}{ PAÍs } \\
& BRASIL & PORTUGAL \\
\hline Bens industriais & 15 & 3 \\
Construção e transporte & 31 & 6 \\
Consumo cíclico & 30 & 11 \\
Consumo não cíclico & 20 & 3 \\
Financeiro e outros & 29 & 7 \\
Materiais básicos & 17 & 6 \\
Petróleo, gás e biocombustíveis & 2 & 1 \\
Tecnologia da informação & 3 & 4 \\
Telecomunicações & 5 & 2 \\
Utilidade pública & 32 & 3 \\
Total de empresas & 184 & 46 \\
\hline
\end{tabular}

Fonte: os autores.

Selecionadas as entidades e reunidas as suas demonstrações financeiras e notas explicativas, identificaram-se as escolhas contábeis possíveis aos gestores, em relação à IAS 38 (2009). No Quadro 2, são destacadas as escolhas contábeis objetos de análise.

Quadro 2 - Escolhas contábeis conforme a IAS 38 - Intangible Assets

\begin{tabular}{|c|c|c|}
\hline \multicolumn{2}{|r|}{ ETAPA } & ESCOLHA CONTÁBIL \\
\hline \multirow{6}{*}{ 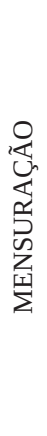 } & Reconhecimento & $\begin{array}{l}\text { Determinado elemento patrimonial intangível é reconhecido no ativo da } \\
\text { entidade? }\end{array}$ \\
\hline & \multirow[b]{2}{*}{ Avaliação } & Avaliação inicial: custo de aquisição, custo de produção ou não evidencia? \\
\hline & & $\begin{array}{l}\text { Avaliação posterior: método do custo, método do valor justo ou não eviden- } \\
\text { cia? }\end{array}$ \\
\hline & \multirow{3}{*}{ Impairment } & A entidade realiza o teste impairment, não realiza ou não evidencia? \\
\hline & & $\begin{array}{l}\text { A entidade amortiza os elementos do intangível, não amortiza ou não evi- } \\
\text { dencia? }\end{array}$ \\
\hline & & $\begin{array}{l}\text { Amortização: método da amortização linear, amortização a saldos decres- } \\
\text { centes, amortização pela produção, outros métodos ou não evidencia? }\end{array}$ \\
\hline
\end{tabular}

Fonte: adaptado de Souza, Silva e Costa (2013).

A análise foi feita nas três etapas de contabilização dos ativos intangíveis: reconhecimento, avaliação e impairment. Para cada etapa, foram identificadas as escolhas contábeis dos gestores, a fim de que se determinasse o número de tratamentos contábeis utilizados, os não utilizados e os não evidenciados pelas entidades. Assim, foram calculados a frequência relativa e o índice de comparabilidade para cada etapa de contabilização e para cada elemento do grupo ativo intangível reconhecido. Na 
sequência, extraiu-se a média desses índices, com a finalidade de se encontrar o grau de comparabilidade do ativo intangível de cada país, para os três períodos.

Para medir o grau de comparabilidade entre as entidades e entre os países, foi utilizado o cálculo do índice T ( $\mathrm{T}$ index), cuja Fórmula foi extraída do estudo de Taplin (2004, p. 61):

$$
\mathrm{T}_{\text {Index }}=\sum_{i=1}^{N} \sum_{j=1}^{N} \sum_{k=1}^{M} \sum_{l=1}^{M} \alpha_{k l} \beta_{i j} P_{k i} P_{l j}
$$

Em que: o T index é o grau de comparabilidade, $\mathrm{N}$ é a quantidade de países analisados, $\mathrm{M}$ é a quantidade de métodos contábeis analisados, é o coeficiente de comparabilidade entre os métodos de contabilidade k e l, é a ponderação para a comparação entre empresas dos países i e j, é a proporção de empresas do país i que utilizam o método contábil k, e é a proporção de empresas do país j que utilizam o método contábil 1 .

O índice varia de 0, representando uma desarmonia completa entre as demonstrações financeiras, a 1, quando há completa harmonia (TAPLIN, 2004), podendo ser interpretado como “[...] a probabilidade de duas ou mais empresas aleatoriamente selecionadas apresentarem práticas contábeis comparáveis.” (SANTOS, 2013, p. 26). Para interpretar o grau de comparabilidade, recorreu-se à escala constante nos estudos de Souza, Silva e Costa (2013), destacada na Tabela 3:

\begin{tabular}{cc} 
Tabela 3 - Interpretação do índice T & \\
\hline Índice $\mathbf{T}$ & Nível de comparabilidade \\
\hline entre 0,700 e 1,000 & Alto \\
entre 0,500 e 0,699 & Médio \\
entre 0,000 e 0,499 & Baixo \\
\hline
\end{tabular}

Fonte: adaptado de Souza, Silva e Costa (2013).

Na coleta de dados, foram identificados 14 itens reconhecidos nos ativos intangíveis das empresas analisadas, quais sejam: acervo técnico, relacionamento com clientes, concessões e licenças, direitos autorais, franquia, folha de pagamento, fundo de comércio, goodwill, marcas e patentes, outros intangíveis, pesquisa e desenvolvimento, servidão de passagem, software e tecnologia. Excluíram-se da análise seis elementos, por estarem reconhecidos apenas nas demonstrações contábeis brasileiras, não possuindo correspondência nos relatórios financeiros das entidades de Portugal. Portanto, a análise dos indicadores de comparabilidade se limitou aos intangíveis re- 
conhecidos que fossem comuns às empresas dos dois países, quais sejam: relacionamento com clientes, concessões e licenças, fundo de comércio, goodwill, marcas e patentes, outros intangíveis, pesquisa e desenvolvimento e software.

Para o cálculo do grau de comparabilidade entre os ativos intangíveis das empresas brasileiras e portuguesas, por setor de atuação, buscou-se analisar apenas os elementos de intangível que fossem comuns a cada setor para os dois países. Assim, a análise setorial baseou-se nos seguintes itens, conforme ilustrado no Quadro 3:

Quadro 3 - Elementos do ativo intangível analisados por setor de atuação

\begin{tabular}{|c|c|}
\hline SETOR & ELEMENTOS DO ATIVO INTANGÍVEL ANALISADOS \\
\hline Bens industriais & Concessões e licenças, goodwill, outros intangíveis e software. \\
\hline $\begin{array}{l}\text { Construção e trans- } \\
\text { porte }\end{array}$ & $\begin{array}{l}\text { Concessões e licenças, goodwill, marcas e patentes, outros intangíveis, pesquisa } \\
\text { e desenvolvimento e software. }\end{array}$ \\
\hline Consumo cíclico & $\begin{array}{l}\text { Concessões e licenças, fundo de comércio, goodwill, marcas e patentes, outros } \\
\text { intangíveis, pesquisa e desenvolvimento e software. }\end{array}$ \\
\hline $\begin{array}{l}\text { Consumo não cí- } \\
\text { clico }\end{array}$ & $\begin{array}{l}\text { Relacionamento com clientes, concessões e licenças, fundo de comércio, } \\
\text { goodwill, marcas e patentes, outros intangíveis, pesquisa e desenvolvimento e } \\
\text { software. }\end{array}$ \\
\hline Financeiro e outros & Goodwill, outros intangíveis, pesquisa e desenvolvimento e software. \\
\hline Materiais básicos & $\begin{array}{l}\text { Relacionamento com clientes, concessões e licenças, goodwill, marcas e paten- } \\
\text { tes, outros intangíveis, pesquisa e desenvolvimento e software. }\end{array}$ \\
\hline $\begin{array}{l}\text { Petróleo, gás e } \\
\text { biocombustíveis }\end{array}$ & Concessões e licenças e goodwill. \\
\hline $\begin{array}{l}\text { Tecnologia da } \\
\text { informação }\end{array}$ & $\begin{array}{l}\text { Concessões e licenças, goodwill, outros intangíveis, pesquisa e desenvolvimen- } \\
\text { to e software. }\end{array}$ \\
\hline Telecomunicações & $\begin{array}{l}\text { Relacionamento com clientes, concessões e licenças, goodwill, outros intangí- } \\
\text { veis, pesquisa e desenvolvimento e software. }\end{array}$ \\
\hline Utilidade pública & Concessões e licenças, goodwill, outros intangíveis e software. \\
\hline
\end{tabular}
Fonte: os autores.

Cabe ressaltar que o cálculo dos índices T nacional e T internacional, constantes na análise de dados, foi realizado por meio do software (T-Index Calculator) cedido pelo criador do índice, o Professor Ross H. Taplin (ao qual desde já agradecemos). Para tanto, foi adotado como critério a modalidade 1(a)2(a)3(a), o que significa, respectivamente: os países foram ponderados na proporção do número de empresas incluídas na amostra daquele país, de forma a possuírem pesos iguais; com foco internacional geral, ou seja, as comparações são feitas entre todas as empresas, independentemente do país; e considerando que múltiplas políticas contábeis não são permitidas (TAPLIN, 2010). 
Quanto à característica da não evidenciação/não aplicação, esta foi tratada nesta pesquisa como mais uma escolha contábil permitida aos gestores. Portanto, na etapa 4 do software T-Index Calculator, foi adotada a opção none.

\section{ANÁLISE DA COMPARABILIDADE DO ATIVO INTANGÍVEL POR SETOR}

Para a análise do grau de comparabilidade entre Brasil e Portugal por setor de atuação, calculou-se o índice T nacional e o T internacional para os elementos dos ativos intangíveis que fossem comuns a cada setor dos dois países, conjuntamente. Na Tabela 4 se exibe o resultado do indicador de comparabilidade por setor de atuação.

Tabela 4 - Comparabilidade das escolhas contábeis brasileiras e portuguesas por setor

(continua)

\begin{tabular}{|c|c|c|c|c|c|c|c|c|c|}
\hline \multirow{2}{*}{$\begin{array}{c}\text { SETOR } \\
\text { Bens industriais }\end{array}$} & \multicolumn{3}{|c|}{$\begin{array}{c}\text { Índice Nacional } \\
\text { Brasil }\end{array}$} & \multicolumn{3}{|c|}{$\begin{array}{c}\text { Índice Nacional } \\
\text { Portugal }\end{array}$} & \multicolumn{3}{|c|}{$\begin{array}{c}\text { Índice Internacional } \\
\text { Brasil e Portugal }\end{array}$} \\
\hline & 2010 & 2011 & 2012 & 2010 & 2011 & 2012 & 2010 & 2011 & 2012 \\
\hline Reconhecimento & 0.707 & 0.702 & 0.707 & 0.778 & 0.778 & 0.778 & 0.677 & 0.677 & 0.682 \\
\hline Avaliação & 0.669 & 0.664 & 0.631 & 0.778 & 0.778 & 0.778 & 0.630 & 0.631 & 0.616 \\
\hline Impairment & 0.708 & 0.714 & 0.689 & 0.815 & 0.815 & 0.815 & 0.678 & 0.691 & 0.670 \\
\hline $\begin{array}{l}\text { Grau de comparabi- } \\
\text { lidade }\end{array}$ & 0.695 & 0.694 & 0.676 & 0.790 & 0.790 & 0.790 & 0.662 & 0.666 & 0.656 \\
\hline $\begin{array}{l}\text { Construção e trans- } \\
\text { portes }\end{array}$ & 2010 & 2011 & 2012 & 2010 & 2011 & 2012 & 2010 & 2011 & 2012 \\
\hline Reconhecimento & 0.630 & 0.627 & 0.630 & 0.648 & 0.648 & 0.648 & 0.598 & 0.595 & 0.596 \\
\hline Avaliação & 0.629 & 0.629 & 0.633 & 0.634 & 0.634 & 0.634 & 0.586 & 0.587 & 0.589 \\
\hline Impairment & 0.685 & 0.692 & 0.694 & 0.642 & 0.642 & 0.642 & 0.633 & 0.640 & 0.643 \\
\hline $\begin{array}{l}\text { Grau de comparabi- } \\
\text { lidade }\end{array}$ & 0.648 & 0.649 & 0.652 & 0.641 & 0.641 & 0.641 & 0.606 & 0.608 & 0.609 \\
\hline Consumo cíclico & 2010 & 2011 & 2012 & 2010 & 2011 & 2012 & 2010 & 2011 & 2012 \\
\hline Reconhecimento & 0.612 & 0.602 & 0.605 & 0.589 & 0.575 & 0.566 & 0.585 & 0.575 & 0.571 \\
\hline Avaliação & 0.611 & 0.609 & 0.600 & 0.579 & 0.569 & 0.560 & 0.578 & 0.575 & 0.562 \\
\hline Impairment & 0.633 & 0.631 & 0.625 & 0.615 & 0.602 & 0.597 & 0.607 & 0.603 & 0.595 \\
\hline $\begin{array}{l}\text { Grau de comparabi- } \\
\text { lidade }\end{array}$ & 0.619 & 0.614 & 0.610 & 0.594 & 0.582 & 0.574 & 0.590 & 0.584 & 0.576 \\
\hline Consumo não cíclico & 2010 & 2011 & 2012 & 2010 & 2011 & 2012 & 2010 & 2011 & 2012 \\
\hline Reconhecimento & 0.706 & 0.678 & 0.678 & 0.667 & 0.667 & 0.667 & 0.672 & 0.661 & 0.661 \\
\hline Avaliação & 0.678 & 0.660 & 0.654 & 0.667 & 0.667 & 0.667 & 0.640 & 0.635 & 0.631 \\
\hline Impairment & 0.719 & 0.692 & 0.681 & 0.667 & 0.667 & 0.667 & 0.675 & 0.663 & 0.654 \\
\hline $\begin{array}{l}\text { Grau de comparabi- } \\
\text { lidade }\end{array}$ & 0.701 & 0.677 & 0.671 & 0.667 & 0.667 & 0.667 & 0.662 & 0.653 & 0.649 \\
\hline
\end{tabular}


(conclusão)

\begin{tabular}{|c|c|c|c|c|c|c|c|c|c|}
\hline \multirow{2}{*}{$\begin{array}{c}\text { SETOR } \\
\text { Financeiro e outros }\end{array}$} & \multicolumn{3}{|c|}{$\begin{array}{c}\text { Índice Nacional } \\
\text { Brasil }\end{array}$} & \multicolumn{3}{|c|}{$\begin{array}{c}\text { Índice Nacional } \\
\text { Portugal } \\
\end{array}$} & \multicolumn{3}{|c|}{$\begin{array}{c}\text { Índice Internacional } \\
\text { Brasil e Portugal }\end{array}$} \\
\hline & 2010 & 2011 & 2012 & 2010 & 2011 & 2012 & 2010 & 2011 & 2012 \\
\hline Reconhecimento & 0.617 & 0.621 & 0.622 & 0.694 & 0.755 & 0.755 & 0.585 & 0.604 & 0.602 \\
\hline Avaliação & 0.634 & 0.621 & 0.647 & 0.633 & 0.694 & 0.694 & 0.569 & 0.564 & 0.570 \\
\hline Impairment & 0.648 & 0.631 & 0.652 & 0.724 & 0.796 & 0.796 & 0.616 & 0.624 & 0.628 \\
\hline $\begin{array}{l}\text { Grau de comparabi- } \\
\text { lidade }\end{array}$ & 0.633 & 0.624 & 0.640 & 0.684 & 0.748 & 0.748 & 0.590 & 0.597 & 0.600 \\
\hline Materiais básicos & 2010 & 2011 & 2012 & 2010 & 2011 & 2012 & 2010 & 2011 & 2012 \\
\hline Reconhecimento & 0.608 & 0.592 & 0.583 & 0.635 & 0.603 & 0.603 & 0.589 & 0.563 & 0.556 \\
\hline Avaliação & 0.607 & 0.574 & 0.568 & 0.635 & 0.603 & 0.603 & 0.585 & 0.561 & 0.557 \\
\hline Impairment & 0.645 & 0.586 & 0.575 & 0.648 & 0.616 & 0.616 & 0.603 & 0.575 & 0.567 \\
\hline $\begin{array}{l}\text { Grau de comparabi- } \\
\text { lidade }\end{array}$ & 0.620 & 0.584 & 0.575 & 0.639 & 0.608 & 0.608 & 0.593 & 0.567 & 0.560 \\
\hline $\begin{array}{l}\text { Petróleo, gás e bio- } \\
\text { combustíves }\end{array}$ & 2010 & 2011 & 2012 & 2010 & 2011 & 2012 & 2010 & 2011 & 2012 \\
\hline Reconhecimento & 0.750 & 0.750 & 0.750 & 1.000 & 1.000 & 1.000 & 0.778 & 0.778 & 0.778 \\
\hline Avaliação & 0.750 & 0.750 & 0.750 & 1.000 & 1.000 & 1.000 & 0.778 & 0.778 & 0.778 \\
\hline Impairment & 0.750 & 0.750 & 0.750 & 1.000 & 1.000 & 1.000 & 0.630 & 0.630 & 0.630 \\
\hline $\begin{array}{l}\text { Grau de comparabi- } \\
\text { lidade }\end{array}$ & 0.750 & 0.750 & 0.750 & 1.000 & 1.000 & 1.000 & 0.728 & 0.728 & 0.728 \\
\hline $\begin{array}{l}\text { Tecnologia da infor- } \\
\text { mação }\end{array}$ & 2010 & 2011 & 2012 & 2010 & 2011 & 2012 & 2010 & 2011 & 2012 \\
\hline Reconhecimento & 0.569 & 0.569 & 0.733 & 0.750 & 0.750 & 0.750 & 0.608 & 0.608 & 0.657 \\
\hline Avaliação & 0.600 & 0.600 & 0.644 & 0.675 & 0.675 & 0.750 & 0.600 & 0.584 & 0.616 \\
\hline Impairment & 0.659 & 0.659 & 0.704 & 0.708 & 0.708 & 0.783 & 0.635 & 0.635 & 0.679 \\
\hline $\begin{array}{l}\text { Grau de comparabi- } \\
\text { lidade }\end{array}$ & 0.610 & 0.610 & 0.694 & 0.711 & 0.711 & 0.761 & 0.615 & 0.609 & 0.651 \\
\hline Telecomunicações & 2010 & 2011 & 2012 & 2010 & 2011 & 2012 & 2010 & 2011 & 2012 \\
\hline Reconhecimento & 0.760 & 0.787 & 0.813 & 0.667 & 0.667 & 0.667 & 0.660 & 0.687 & 0.714 \\
\hline Avaliação & 0.680 & 0.693 & 0.720 & 0.667 & 0.667 & 0.667 & 0.612 & 0.633 & 0.660 \\
\hline Impairment & 0.742 & 0.720 & 0.702 & 0.667 & 0.667 & 0.667 & 0.669 & 0.653 & 0.651 \\
\hline $\begin{array}{l}\text { Grau de comparabi- } \\
\text { lidade }\end{array}$ & 0.727 & 0.733 & 0.745 & 0.667 & 0.667 & 0.667 & 0.647 & 0.658 & 0.675 \\
\hline Utilidade pública & 2010 & 2011 & 2012 & 2010 & 2011 & 2012 & 2010 & 2011 & 2012 \\
\hline Reconhecimento & 0.695 & 0.693 & 0.687 & 0.778 & 0.778 & 0.778 & 0.673 & 0.672 & 0.666 \\
\hline Avaliação & 0.605 & 0.599 & 0.605 & 0.778 & 0.778 & 0.778 & 0.581 & 0.575 & 0.579 \\
\hline Impairment & 0.613 & 0.611 & 0.612 & 0.778 & 0.778 & 0.778 & 0.604 & 0.602 & 0.602 \\
\hline $\begin{array}{l}\text { Grau de comparabi- } \\
\text { lidade }\end{array}$ & 0.638 & 0.634 & 0.635 & 0.778 & 0.778 & 0.778 & 0.619 & 0.616 & 0.616 \\
\hline
\end{tabular}

Fonte: os autores. 
Para o caso brasileiro, apenas os setores de petróleo, gás e biocombustíveis e telecomunicações expuseram um grau de comparabilidade alto. Todos os demais setores brasileiros obtiveram uma comparabilidade média em relação às demonstrações contábeis em ativos intangíveis, em todos os períodos selecionados.

Cabe destacar, também, que a comparabilidade dos ativos intangíveis está diminuindo com o passar dos exercícios sociais, exceto para os setores de construção e transporte, tecnologia da informação e telecomunicações, que registraram índices crescentes.

Quanto a Portugal, este se diferenciou do Brasil no sentido de que apresentou três setores de atuação (bens industriais, tecnologia da informação e utilidade pública) com índices elevados e um setor (petróleo, gás e biocombustíveis) com grau máximo de comparabilidade. Ademais, ao se analisar a evolução dos indicadores, percebe-se que a maioria dos setores (seis) evidenciou uma estabilidade no grau de comparabilidade na mensuração dos seus ativos intangíveis, para os três períodos. Se forem considerados apenas os dois últimos anos, essa estabilidade aumenta para oito setores (acrescentam-se os setores financeiro e outros e materiais básicos). Essa estabilidade nas práticas contábeis em ativos intangíveis das entidades portuguesas poderia remeter a uma possível harmonização de fato (prática).

Curiosamente, o setor de consumo cíclico foi o único setor português que apontou índice de comparabilidade abaixo de 0,6 (e em todos os períodos!) e decrescente ao longo do tempo. Os demais setores revelaram indicadores com valores superiores a 0,6, além de um grau de comparabilidade estável (na maioria dos casos) ou crescente.

No que se refere à comparabilidade das escolhas contábeis em ativos intangíveis de entidades pertencentes ao Brasil e a Portugal ( $\mathrm{T}$ index internacional), constatou-se que, para o setor de petróleo, gás e biocombustíveis a comparabilidade é alta e permanece estável nos três períodos analisados. Por exemplo, se forem selecionadas duas entidades pertencentes ao setor de petróleo, gás e biocombustíveis, aleatoriamente, no Brasil e em Portugal, há 72,8\% de chance de essas empresas adotarem as mesmas práticas contábeis em seus ativos intangíveis.

Os setores de consumo cíclico, financeiro e outros e materiais básicos registraram uma comparabilidade média, porém com valores inferiores a 0,6. Os demais setores revelaram uma comparabilidade média (mas com valores próximos a 0,65) em todos os períodos analisados. 
Cumpre salientar que, quanto à análise por setor, verifica-se que as empresas portuguesas indicaram grau de comparabilidade maior do que as entidades brasileiras, em seis setores (bens industriais, financeiro e outros, materiais básicos, petróleo, gás e biocombustíveis, tecnologia da informação, e utilidade pública), enquanto o Brasil se destacou em apenas quatro setores (construção e transporte, consumo cíclico, consumo não cíclico, e telecomunicações).

De maneira geral, com base nos resultados encontrados, pode-se extrair que existe comparabilidade entre as práticas contábeis em ativos intangíveis de entidades pertencentes ao Brasil e a Portugal, independente do setor de atuação e do período analisado.

\section{ANÁLISE DA COMPARABILIDADE DO ATIVO INTANGÍVEL POR PAÍS}

Partindo-se para a análise do grau de comparabilidade dos países internamente e entre eles, primeiramente, calculou-se o T index nacional para Brasil e para Portugal, isoladamente, e, depois, calculou-se o $\mathrm{T}$ index internacional para os dois países, conforme a Tabela 5 .

Tabela 5 - Índice de comparabilidade nacional e internacional

\begin{tabular}{|c|c|c|c|c|c|c|c|c|c|}
\hline \multirow{2}{*}{$\begin{array}{c}\text { ESCOLHAS } \\
\text { CONTÁBEIS } \\
\text { NO INTANGÍ- } \\
\text { VEL }\end{array}$} & \multicolumn{3}{|c|}{ T NACIONAL BRASIL } & \multicolumn{3}{|c|}{$\begin{array}{l}\text { T NACIONAL } \\
\text { PORTUGAL }\end{array}$} & \multicolumn{3}{|c|}{$\begin{array}{c}\text { T INDEX } \\
\text { INTERNACIONAL }\end{array}$} \\
\hline & 2010 & 2011 & 2012 & 2010 & 2011 & 2012 & 2010 & 2011 & 2012 \\
\hline Reconhecimento & 0.661 & 0.647 & 0.643 & 0.627 & 0.625 & 0.629 & 0.641 & 0.632 & 0.628 \\
\hline Avaliação & 0.671 & 0.659 & 0.653 & 0.619 & 0.617 & 0.621 & 0.641 & 0.633 & 0.629 \\
\hline Avaliação inicial & 0.652 & 0.640 & 0.633 & 0.612 & 0.610 & 0.613 & 0.628 & 0.619 & 0.613 \\
\hline $\begin{array}{l}\text { Avaliação pos- } \\
\text { terior }\end{array}$ & 0.689 & 0.678 & 0.673 & 0.627 & 0.625 & 0.629 & 0.655 & 0.647 & 0.644 \\
\hline Impairment & 0.689 & 0.674 & 0.668 & 0.641 & 0.643 & 0.645 & 0.668 & 0.657 & 0.652 \\
\hline Teste impairment & 0.658 & 0.644 & 0.640 & 0.629 & 0.627 & 0.629 & 0.636 & 0.627 & 0.624 \\
\hline Amortização & 0.644 & 0.625 & 0.619 & 0.589 & 0.592 & 0.596 & 0.618 & 0.605 & 0.600 \\
\hline $\begin{array}{l}\text { Métodos de } \\
\text { amortização }\end{array}$ & 0.765 & 0.752 & 0.744 & 0.705 & 0.709 & 0.710 & 0.748 & 0.739 & 0.733 \\
\hline $\begin{array}{l}\text { Grau de compa- } \\
\text { rabilidade }\end{array}$ & 0.673 & 0.660 & 0.654 & 0.629 & 0.628 & 0.632 & 0.650 & 0.640 & 0.636 \\
\hline
\end{tabular}

Fonte: os autores. 
Quanto ao Brasil, percebeu-se uma comparabilidade média nas três etapas de mensuração do ativo intangível, em todos os períodos. Ao se analisar a evolução do índice ao longo dos três anos, verificou-se uma ligeira queda, ou seja, o grau de comparabilidade geral dos ativos intangíveis está diminuindo com o passar dos exercícios sociais. Entretanto, ao se analisarem as cinco fases de mensuração, percebeu-se que os maiores índices de comparabilidade acontecem nos métodos de amortização, momento em que há maior número da mesma prática contábil. Esse achado contrariou os resultados da pesquisa de Souza, Silva e Costa (2013), que identificaram o menor índice de comparabilidade nessa fase de mensuração.

Porém, os resultados desta pesquisa podem ser justificados em virtude da cultura brasileira em valer-se do método linear de amortização, mesmo que outros métodos sejam possíveis e mais adequados. Ademais, a Agência Nacional de Energia Elétrica (Aneel) regulamenta as práticas de amortização dos ativos intangíveis das companhias de Energia Elétrica do Brasil (17,32\% da amostra analisada) e determinou o método linear para o cálculo da amortização de seus ativos intangíveis. Essa justificativa corrobora as constatações dos estudos de Jaafar e McLeay (2007), que trazem que as práticas contábeis refletem, sistematicamente, as regras e os regulamentos do país no qual a empresa está registrada.

Ao se analisarem os índices de comparabilidade dos ativos intangíveis das empresas de Portugal, notou-se que ele também apresentaram uma comparabilidade média dentro do País e ao longo do tempo. Cabe destacar, ainda, que apesar de ter maior experiência com as normas internacionais de contabilidade (oito anos de experiência), Portugal registrou índices de comparabilidade inferiores aos identificados no Brasil (três anos de experiência).

Em conformidade com o caso brasileiro, verificou-se que os maiores índices de comparabilidade ocorreram na fase em que há mais alternativas contábeis (métodos de amortização). Assim como no Brasil, a comparabilidade desse item foi elevada, pelo fato de, apesar da existência de, no mínimo, quatro escolhas contábeis (método linear, saldos decrescentes, unidades produzidas ou outros métodos), as entidades portuguesas continuarem optando pelo método linear de amortização de ativos intangíveis.

Poder-se-ia afirmar, erroneamente, que esses resultados contrariam as constatações da pesquisa de Haller e Wehrfritz (2013), as quais trouxeram que as escolhas contábeis explícitas nas IFRS podem provocar diferenças nas comparações internacionais de empresas e, em consequência, a redução da comparabilidade dos relatórios financeiros de entidades de diferentes países. Entretanto, o fato de o maior grau de 
comparabilidade ter se verificado na fase em que mais se apresentam escolhas contábeis indica apenas que tanto as empresas brasileiras quanto as portuguesas optaram pelo mesmo método contábil de amortização (método linear), apesar da existência de pelo menos três outros. Pode ser que, para o tratamento contábil dos ativos intangíveis, o método linear seja o que mais representa o padrão de consumo dos benefícios econômicos futuros pelas entidades.

Quanto à comparabilidade entre os países, ilustrada por meio do índice $\mathrm{T}$ internacional, constatou-se que os dois países denotam uma média comparabilidade nas suas práticas contábeis em relação aos ativos intangíveis, nos três períodos analisados, mesmo se apresentando com valores decrescentes. Esse resultado mostra que, se duas entidades do Brasil e de Portugal forem selecionadas aleatoriamente em 2012, por exemplo, há 60,1\% de chance de que elas tenham optado pelas mesmas políticas contábeis quanto aos seus ativos intangíveis.

Assim, de maneira geral, a partir dos dados explanados, constatou-se que existe comparabilidade entre as práticas contábeis em ativos intangíveis de entidades brasileiras e portuguesas, independente da fase de mensuração e do período analisado.

\section{CONSIDERAÇÕES FINAIS}

Na presente pesquisa teve-se como objetivo identificar o grau de comparabilidade das demonstrações financeiras das companhias abertas do Brasil e de Portugal em relação às escolhas contábeis para ativos intangíveis. Nesse prisma, visando alcançar o objetivo traçado, foram analisadas as companhias abertas listadas, em 2013, na BM\&FBOVESPA e na NYSE Euronext Lisbon, no horizonte temporal de 2010 a 2012.

Por meio dos resultados encontrados, verificou-se que, apesar das escolhas contábeis presentes na IAS 38, existe comparabilidade entre as práticas contábeis das empresas brasileiras e portuguesas, em todos os períodos e setores elencados neste estudo. Os resultados encontrados nesta pesquisa podem ter sido fruto das fortes relações existentes entre Brasil e Portugal desde o ano 1500, quando da colonização, até os dias atuais, em que os dois países mantêm entre si intensas relações comerciais. Essa antiga “parceria”, que resultou em culturas similares (a exemplo da língua), pode ter possibilitado práticas contábeis semelhantes em relação ao ativo intangível e, em consequência, proporcionado a comparabilidade de seus relatórios financeiros.

Quanto a essa comparabilidade entre os países (indicada por meio do T internacional), averiguou-se que a comparabilidade das práticas contábeis em ativos intan- 
gíveis do Brasil e de Portugal foi média, nos três períodos analisados, e com valores decrescentes ao longo dos exercícios sociais (0,650; 0,640; 0,636, respectivamente).

Em relação à comparabilidade de cada país, separadamente (indicada pelo T nacional), observou-se que, embora tenha maior experiência com as normas internacionais de contabilidade, Portugal apresentou índices de comparabilidade inferiores aos revelados no Brasil. Posto que essa análise comparou nações que adotaram as IFRS em períodos diferentes, percebeu-se que a experiência com as IFRS não necessariamente garante maior comparabilidade das práticas contábeis. Uma possível explicação seria o fato de a experiência vivenciada em um país tornar-se referência para situações similares a serem vivenciadas por países que iniciam o seu processo de convergência.

No tópico referente aos resultados por setor, detectou-se que Portugal apresentou uma comparabilidade maior na maioria dos setores (60\%) quando comparado ao Brasil (40\%). Por outro lado, os resultados da comparabilidade dos ativos intangíveis por país apontaram índices inferiores para Portugal em relação aos identificados no Brasil.

Esses resultados permitem fazer uma alusão ao estudo de Jaafar e McLeay (2007), os quais ressaltam que as práticas contábeis não dependem apenas das regulamentações do país, mas também das operações da entidade referentes às diversas especificidades inerentes aos negócios, que exigem diferentes formas de mensuração, reconhecimento e divulgação. De acordo com esses autores, a convergência contábil seria alcançada quando, sob as mesmas operações, fossem adotadas as mesmas práticas contábeis, independente do domicílio. Dessa forma, como em Portugal encontrou-se um maior grau de comparabilidade por setor de atuação (e não por país), infere-se que a convergência possa estar acontecendo de forma mais efetiva naquele País.

Em relação às fases de mensuração dos ativos intangíveis, os índices de comparabilidade mais elevados se concentraram nos métodos de amortização, que, surpreendentemente, é o momento em que há maior número de escolhas contábeis. Possíveis justificativas foram tecidas na seção anterior, mas, entre elas, cumpre destacar o fato de as empresas brasileiras e portuguesas terem optado pelo mesmo método de amortização (método linear), possivelmente, por ser o método que melhor representa o consumo dos benefícios econômicos futuros pelas entidades.

Uma vez que os reflexos das escolhas contábeis, na comparabilidade dos relatórios financeiros, estão sendo objetos de constantes pesquisas, os resultados encontrados neste estudo contribuem com a literatura internacional, ao passo que complementam estudos anteriores: Cairns et al. (2011), Tudor e Dragu (2010), Haller e 
Wehrfritz (2013), Souza, Silva e Costa (2013). Complementam ao identificarem que as escolhas contábeis apresentadas na IAS 38 permitem uma comparabilidade das demonstrações contábeis das companhias abertas de diferentes países e ao mostrarem que existe uma convergência, de fato, dos padrões contábeis nacionais ao padrão contábil internacional (IFRS).

Com a pesquisa pretendeu-se contribuir com a prática contábil, ao possibilitar aos usuários compararem os resultados e práticas contábeis entre empresas ao longo do tempo, bem como entre países distintos. Para os órgãos reguladores e outros que investigam o processo de convergência contábil, espera-se, a partir dos resultados aqui descritos, remeter evidências de que há um grau médio de comparabilidade entre as demonstrações contábeis em relação ao ativo intangível e sinalizar, por meio da análise do horizonte temporal, que essa comparabilidade tem diminuído ao longo dos anos, subsidiando futuros estudos e decisões quanto à melhoria desse cenário.

A generalização dos resultados encontrados se limita em virtude de a investigação ter ocorrido apenas a respeito de dois países e sobre os ativos intangíveis. Sugere-se, para futuras pesquisas, aumentar o número de países analisados, visando identificar, de forma ampla, se os resultados aqui apresentados se aplicam a um número maior de países. Sugere-se, também, analisar um número maior de normas contábeis, de forma a ampliar o número de escolhas contábeis permitidas, e, assim, colaborar para a literatura contábil e para o processo de convergência contábil global.

\section{REFERÊNCIAS}

AVELINO, B. C.; PINHEIRO, L. E. T.; LAMOUNIER, W. M. Evidenciação de ativos intangíveis: estudo empírico em companhias abertas. Revista de Contabilidade e Organizações, v. 6, n. 14, p. 22-45, 2012.

BARTH, M. E. Global Financial Reporting: Implications for U.S. Academics. American Accounting Association, v. 83, i. 5, p. 1159-1179, 2008.

BRASIL e Portugal estão mudando o patamar da relação, afirma Dilma. Palácio do Planalto - Presidência da República, Brasília, DF, 10 jun. 2013. Disponível em: $<$ http://blog.planalto.gov.br/brasil-e-portugal-estao-mudando-o-patamar-da-relacao-afirma-dilma/>. Acesso em: 03 dez. 2013. 
BRASIL. Lei n. 11.636, de 28 de dezembro de 2007. Altera e revoga dispositivos da Lei $n^{-6} 6.404$, de 15 de dezembro de 1976, e da Lei $\mathrm{n}^{-0} 6.385$, de 7 de dezembro de 1976, e estende às sociedades de grande porte disposições relativas à elaboração e divulgação de demonstrações financeiras. Diário Oficial da União, Brasília, DF, 28 dez. 2007. Disponível em: <http://www.planalto.gov.br/ccivil_03/_ato20072010/2007/lei/111638.htm>. Acesso em: 23 dez. 2013.

CAIRNS, D. et al. IFRS fair value measurement and accounting policy choice in the United Kingdom and Australia. The British Accounting Review, v. 43, i. 1, p. 1-21, 2011.

COMITÊ DE PRONUNCIAMENTOS CONTÁBEIS. Origem. 2013a. Disponível em: <http://www.cpc.org.br/oque.htm>. Acesso em: 22 dez. 2013.

COMITÊ DE PRONUNCIAMENTOS CONTÁBEIS. Pronunciamentos Técnicos. 2013b. Disponível em: <http://www.cpc.org.br/pronunciamentosIndex.php>. Acesso em: 26 dez. 2013.

DRAGU, I. M. Diversity of national and international accounting practices: the case of intangible assets. Directory of Open Access Journals, University of Oradea, 2010.

EKBERG, M.; LINDGREN, L. Accounting of intangibles under IFRS - a comparative study of Sweden and Australia. 2007. Master Thesis (Department of Financial Reporting and Analysis - School of Business, Economics and Law)-Gothenburg University, Gothenburg, 2007.

EUROPEAN PARLIAMENT. Uniform rules for international accounting standards from 2005 onwards. European Parliament Daily Notebook, 2002. Disponível em: <http://www.europarl.europa.eu/sides/getDoc.do?pubRef=-//EP//TEXT+PRESS+DN-20020312-1+0+DOC+XML+V0//EN\#SECTION5>. Acesso em: 26 dez. 2013.

FIELDS, T. D.; LYS, T. Z.; VINCENT, L. Empirical research on accounting choice. Journal of Accounting and Economics, v. 31, p. 255-307, 2001.

FRERI, M. R.; SALOTTI, B. M. Comparabilidade de empresas administradoras de shoppings centers do mercado de capitais brasileiro. Revista de Contabilidade do Mestrado em Ciências Contábeis da UERJ, v. 18, n. 1, p. 28-45, 2013.

FUNDAÇÃO IFRS. Quem somos e o que fazemos. 2013. Disponível em: < http:// www.ifrs.org/The-organisation/Documents/2013/Who-We-Are-Portuguese-2013. pdf>. Acesso em: 26 dez. 2013. 
GABRIEL, F.; CORRAR, L. J. Gerenciamento de resultados e de capital no sistema bancário brasileiro: uma investigação empírica nas aplicações em títulos e valores mobiliários. Revista de Contabilidade do Mestrado em Ciências Contábeis da UERJ, v. 15, n. 2, p. 49-62, 2010.

GE, W.; MATSUMOTO, D.; ZHANG, J. L. Do CFOs have style? An empirical investigation of the effect of individual CFOs on accounting practices. Contemporary Accounting Research, v. 28, i. 4, p. 1141-1179, 2011.

GOLDMAN ACADEMY. Goldman Academy Business School, 2013. Disponível em: $<$ http://academy.goldman.com.pt/legislacao_UE-IAS.html>. Acesso em: 26 dez. 2013.

GOULART, A. M. C. Gerenciamento de resultados contábeis em instituições financeiras no Brasil. 2007. 2019 p. Tese (Doutorado em Ciências Contábeis)-Universidade de São Paulo, São Paulo, 2007.

HALLER, A.; WEHRFRITZ, M. The impact of national GAAP and accounting traditions on IFRS policy selection: evidence from Germany and the UK. Journal of International Accounting, Auditing and Taxation, v. 22, p. 39-56, 2013.

IAS PLUS. IAS 38 - Intangible Assets. 2009. Disponível em: <http://www.iasplus.com/en/standards/ias/ias38> Acesso em: 26 dez. 2013.

IAS PLUS. The Conceptual Framework for Financial Reporting. Disponível em: $<$ http://www.iasplus.com>. Acesso em: 26 dez. 2016.

JAAFAR, A.; MCLEAY, S. Country effects and sector effects on the harmonization of accounting policy choice. Abacus, v. 43, i. 2, p. 156-189, 2007.

KPMG. IFRS - International Financial Reporting Standards. 2013. Disponível em: <http://www.kpmg.com/br/pt/servicos/audit/paginas/ifrs.aspx> . Acesso em: 26 dez. 2013.

KUMAR, G. Voluntary disclosures of intangibles information by U.S. - listed Asian companies. Journal of International Accounting, Auditing and Taxation, v. 22, p. 109-118, 2013.

LEITE, C. E. B. A evolução das Ciências Contábeis no Brasil. São Paulo: FGV, 2005.

LEMES, S.; CARVALHO, L. N. G. Comparabilidade entre o resultado em BR GAAP e U.S. GAAP: evidências das companhias abertas brasileiras listadas nas bolsas norte-americanas. Revista Contabilidade \& Finanças, v. 20, n. 50, p. 25-45, 2009. 
LEMES, S.; CARVALHO, N. Contabilidade Internacional para Graduação. São Paulo: Atlas, 2010.

LORENCINI, F. D.; COSTA, F. M. Escolhas contábeis no Brasil: identificação das características das companhias que optaram pela manutenção versus baixa dos saldos do ativo diferido. Revista Contabilidade \& Finanças, v. 23, n. 58, p. 52-64, 2012.

MALAQUIAS, R. F. Disclosure de instrumentos financeiros segundo as normas internacionais de contabilidade: evidências empíricas de empresas brasileiras. 2008. Dissertação (Mestrado em Administração)-Universidade Federal de Uberlândia, Uberlândia, 2008.

MARTINEZ, A. L. Gerenciamento dos resultados contábeis: estudo empírico das companhias abertas brasileiras. 2001. 167 p. Tese (Doutorado em Ciências Contábeis)-Universidade de São Paulo, São Paulo, 2001.

MURCIA, F. D.; WERGES, A. Escolhas contábeis no mercado brasileiro: divulgação voluntária de informações versus gerenciamento de resultados. Revista Universo Contábil, v. 7, n. 2, p. 28-44, 2011.

OLIVEIRA, V. A.; LEMES, S. Nível de convergência dos princípios contábeis brasileiros e norte-americanos às normas do IASB: uma contribuição para a adoção das IFRS por empresas brasileiras. Revista Contabilidade \& Finanças, v. 22, n. 56, p. 155-173, 2011.

PELEIAS, I. R.; BACCI, J. Pequena cronologia do desenvolvimento contábil no Brasil: os primeiros pensadores, a padronização contábil e os congressos brasileiros de contabilidade. Revista Administração On Line - FECAP, v. 5, n. 3, p. 39-54, 2004.

PENG, S.; SMITH, J. V. D. A. Chinese GAAP and IFRS: an analysis of the convergence process. Journal of International Accounting, Auditing and Taxation, v. 19, p. 16-34, 2010.

PREFÁCIO ÀS IFRS. Preface to International Financial Reporting Standards. 2007. Disponível em: <http:// mf.rks-gov.net/Portals/0/.../SNRF-en/Preface.DOC>. Acesso em: 26 dez. 2013.

SANTOS, L. A. A. Comparabilidade das Demonstrações Contábeis Brasileiras em 2009 e 2010. 2013. Dissertação (Mestrado em Administração)-Universidade Federal de Uberlândia, Uberlândia, 2013.

SCHIPPER, K. Principles-based accounting standards. Accounting Horizons, v. 17, p. 61-72, 2003. 
SCHMIDT, P.; SANTOS, J. L. Ativos Intangíveis nas Normas Internacionais IASB. In: CONVENÇÃO DE CONTABILIDADE DO RIO GRANDE DO SUL, 9., 2003, Gramado. Anais... Gramado, 2003. Disponível em: <http://ccontabeis.com.br/ conv/t01.pdf >. Acesso em: 26 dez. 2013.

SOUZA, F. E. A.; SILVA, M. H.; COSTA, P. S. A comparabilidade das escolhas contábeis na avaliação de ativos intangíveis de companhias abertas brasileiras. In: SEMINÁRIOS EM ADMINISTRAÇÃO FEA/USP, 16., 2013, São Paulo. Anais... São Paulo, 2013.

STERGIOS, A.; LASKARIDOU, E. C. Have met IASs Accounting Harmonization? The case of Greek Listed Companies. International Conference on Applied Economics - ICOAE, p. 51-60, 2008.

TAPLIN, R. H. A unified approach to the measurement of international accounting harmony. Accounting and Business Research, v. 34, i. 1, p. 57-73, 2004.

TAPLIN, R. H. Statistical inference using the T index to quantify the level of comparability between accounts. Accounting and Business Research, v. 40, i. 1, p. 75-103, 2010.

TUDOR, A. T; DRAGU, I. M. Impact of International Financial Reporting Standards on Accounting Practices Harmonization within European Union - Particular Case of Intangible Assets. Annales Universitatis Apulensis Series Oeconomica, v. 12, i. 1, p. 191-206, 2010.

VAN DER TAS, L. G. Measuring harmonization of financial reporting practice. Accounting and Business Research, v. 18, i. 70, p. 157-169, 1988.

WATTS, R. L. Accounting choice theory and market-based research in accounting. British Accounting Review, v. 24, p. 235-267, 1992.

Como citar este artigo:

ABNT

SOUZA, Flaida Êmine Alves de; BOTINHA, Reiner Alves; LEMES, Sirlei. A comparabilidade das escolhas contábeis na mensuração de ativos intangíveis de companhias abertas brasileiras e portuguesas. RACE, Revista de Administração, Contabilidade e Economia, Joaçaba: Ed. Unoesc, v. 15, n. 3, p. 1117-1142, set./dez. 2016. Disponível em: <http://editora.unoesc.edu.br/index.php/race>. Acesso em: dia/ mês/ano. 


\section{APA}

Souza, F. Ê. A. de, Botinha, R. A., \& Lemes, S. (2016). A comparabilidade das escolhas contábeis na mensuração de ativos intangíveis de companhias abertas brasileiras e portuguesas. RACE, Revista de Administração, Contabilidade e Economia, 15(3), 1117-1142. Recuperado em dia/mês/ano, de http://editora.unoesc.edu.br/index.php/race 